\title{
A TECHNIQUE FOR THE COLLECTION BY FISTULA OF EPIDIDYMAL SPERMATOZOA FROM THE RAT
}

\author{
D. P. GILMORE, R. H. HOOKER AND M. G. CHANG \\ The Worcester Foundation for Experimental Biology, \\ Shrewsbury, Massachusetts, U.S.A.
}

(Received 2nd November 1970)

Since the successful establishment of a fistula of the vas deferens in the ram by White, Larson \& Wales (1959), various techniques have been devised for the collection of epididymal spermatozoa from bulls, rams and boars. Wierzbowski $\&$ Wierzchos (1969) list authors who have undertaken such work. Recently, we have developed a fistula method for the regular collection of epididymal spermatozoa from the rat.

Because of its extremely small diameter, the rat's vas deferens is unsuitable for cannulation and when brought directly to the surface of the skin, it soon becomes obstructed and covered by closure of the skin above it. It can, however, be anastomosed either to the small or to the large intestine by simple implantation and will generally remain open and continue to function indefinitely. Utilizing this principle to construct a fistula of the vas deferens, the following procedure has now been frequently undertaken in mature Sprague-Dawley rats (Charles River CD strain).

Under Nembutal anaesthesia, the abdomen was opened through a lower midline incision. The end of the caecum was carefully isolated from the caecum proper so that a good blood supply was preserved. A longitudinal opening, about $1 \mathrm{~cm}$ in length, was then made in the antimesenteric border of this isolated segment thus forming a pouch. In each dorsolateral aspect of the pouch, a small stab wound was made through which the vasa deferentia were brought out by means of traction sutures. The vasa deferentia were then divided and secured in position by a single fine suture. The four quadrants of the pouch were sutured to the parietal peritoneum to prevent herniation and the wound was closed about the pouch orifice. A small semicircle of skin was excised on either side of the pouch orifice to assist eversion of the stoma and the latter was then sutured to the surrounding skin, leaving an opening approximately $1 \mathrm{~cm}$ in diameter. After the operation, the pouch was occasionally flushed with a small quantity of saline until healing had been established. Text-figure 1 illustrates the various steps undertaken during the construction of the fistula.

Within a few days of the operation, approximately $0.005 \mathrm{ml}$ of spermatozoa can readily be collected from the pouch after electrical stimulation of the anaesthetized animal (Plate 1), using a single lubricated bipolar electrode similar to that described by Scott \& Dziuk (1959). Direct electrical stimulation of the divided vas deferens in intact anaesthetized rats was observed to cause 
D. P. Gilmore et al.

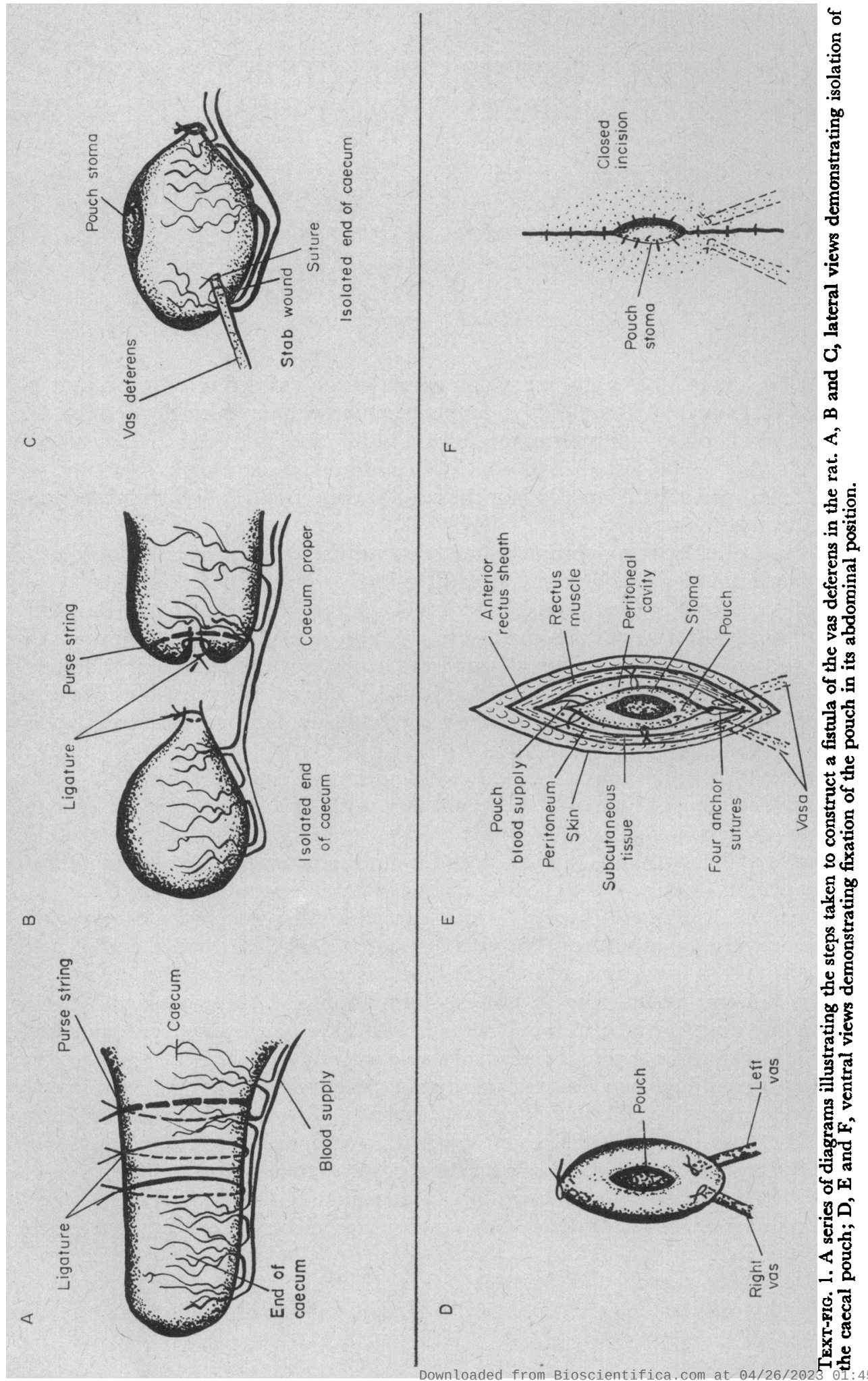


PLATE 1

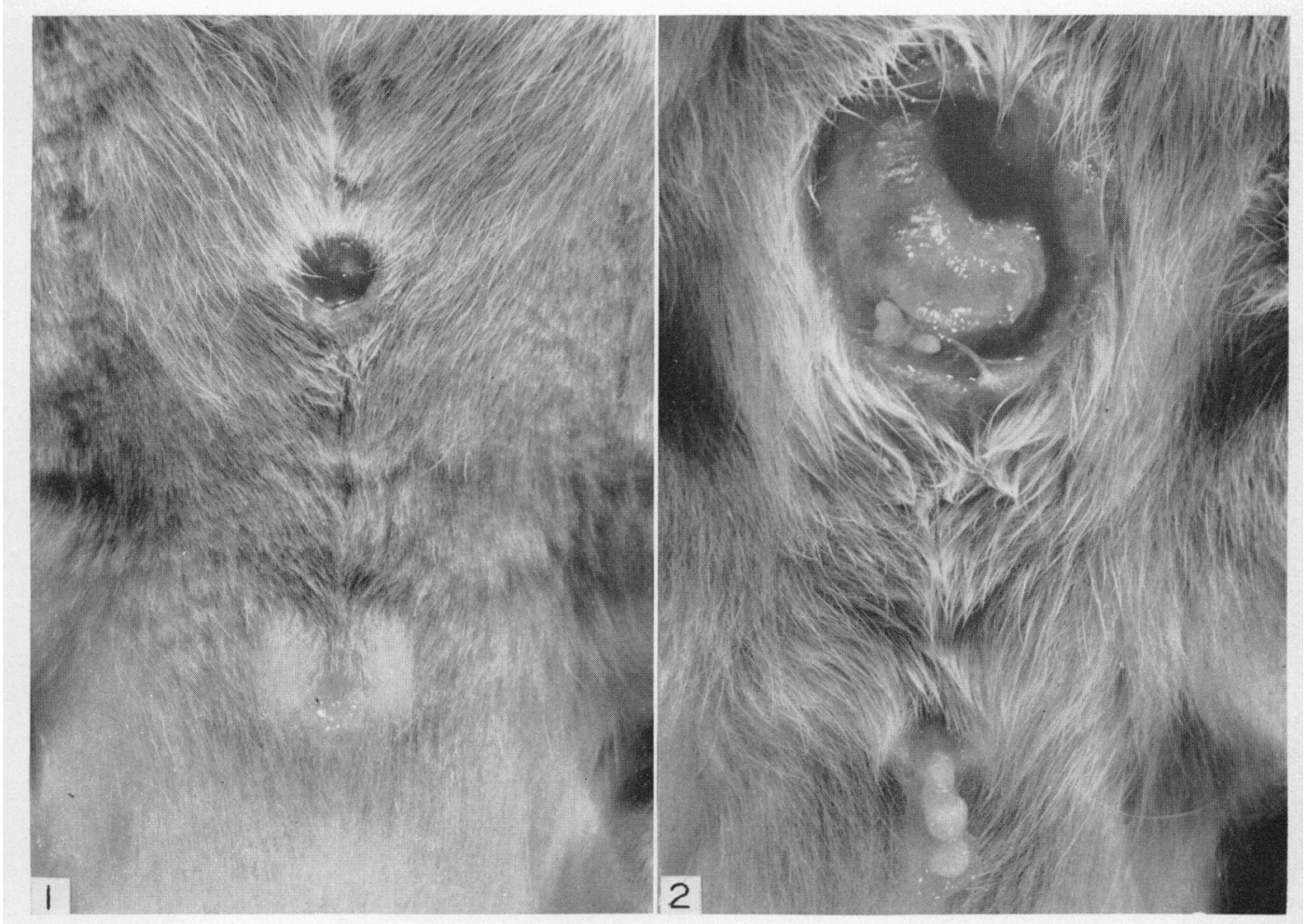

FIs. 1. Established fistula of the vasa deferentia. A droplet of seminal fluid can be seen at the tip of the penis.

Fic. 2. Pouch certed to show the emission of spermatozon which appear as thick white globules near the lower edge of the pouch. The penis, with seminal fluid adhering. is also apparent. 
contraction and foreshortening accompanied by an outpouring of spermatozoa. It appears likely that spermatozoa which flow into the pouch after stimulation are squeezed out in a similar manner.

Males with fistulae show normal libido and will copulate with female rats placed in their cages. The copulation is accompanied by an emission of spermatozoa into the pouch.

On twenty-two occasions after application of an electrical stimulus, the spermatozoa appearing in the pouch were counted. Values ranging from $3.2 \times$ $10^{6}$ to $17.6 \times 10^{6}$ were obtained, with a mean of $7.3 \times 10^{6}( \pm 0.9$ S.E.). These values are considerably less than the $60 \times 10^{6}$ estimated by Blandau \& Odor (1949) to occur in the normal ejaculate of the rat. The motility of spermatozoa collected from the pouch was, however, generally good. Spermatozoa aspirated from the pouch in $0.05 \mathrm{ml}$ Hanks' solution were injected into the upper right uterus of twenty pro-oestrous female rats 4 to $6 \mathrm{hr}$ before the expected time of ovulation. Each rat was subjected to cervical stimulation with an electric vibrator on the evening of pro-oestrus and morning of oestrus to induce a pseudopregnant state. All twenty animals were killed and examined 10 days later. At autopsy, four animals were found to be pregnant. There were three implantations in three of these rats and four in the other.

A fistula, as described above, has now been established in thirty-eight rats. One of these animals has already survived for 5 months with a patent fistula. Of the thirty rats so far killed at periods varying from 9 to 63 days after operation, both implanted vasa deferentia were functioning well in twelve of the rats up to the time of autopsy. In four instances, one vas had pulled free from the pouch and a sperm granuloma had developed on the other. Unilateral sperm granulomata had developed in six animals and bilateral granulomata in eleven, but in only one rat did the pouch itself break down. In two rats found to have bilateral granulomata at autopsy, the fistulae functioned until the 39 th and 55th day after operation, respectively, and in only three rats did we fail to obtain any spermatozoa at all from the pouch. In cases where a unilateral granuloma developed, the unobstructed vas deferens continued to function normally.

Early attempts to simplify the operation by ligating, instead of dividing, the caecum failed. In nine instances where this was attempted, the silk ligatures loosened or were absorbed within 1 or 2 weeks of operation and caecal material began to appear in the pouch, necessitating a return to our standard procedure.

We believe this technique could be successfully applied to other laboratory animals and provide a useful and inexpensive method for the regular collection of epididymal spermatozoa.

The authors would like to thank Mrs Rose Bartke and Mrs Anita Hooker for their excellent technical assistance. This work was supported by a grant from USPHS (GM 14370).

\section{REFERENCES}

BLANDAU, R. J. \& ODOR, D. L. (1949) The total number of spermatozoa reaching various segments of the reproductive tract in the female albino rat at intervals after insemination. Anat. Rec. 103, 93. 
Scotr, J. V. \& Dzurk, P. J. (1959) Evaluation of the electro-ejaculation technique and spermatozoa thus obtained from rats, mice and guinea pigs. Anat. Rec. 133, 655 .

White, I. G., LARsen, L. H. \& WALEs, R. G. (1959) Method for the in vivo collection of epididymal spermatozoa and for their comparison with ejaculated cells. Fert. Steril. 10, 571.

Wierzbowski, S. \& Wierzchos, E. (1969) Cannulation of the vas deferens in the boar. F. Reprod. Fert. $19,173$. 